\title{
Cross sectional echocardiographic assessment of left ventricular volume and ejection fraction in patients with tetralogy of Fallot Comparison with biplane angiographic measurements
}

\author{
I OBERHÄNSLI, B FRIEDLI \\ From the Pediatric Cardiology Unit, University of Geneva Medical School, Geneva, Switzerland
}

SUMmaRY To evaluate the usefulness and accuracy of calculating left ventricular volume and ejection fraction from cross sectional echocardiograms in patients with tetralogy of Fallot, 28 patients were studied within 24 hours of cineangiography. Indexed end diastolic and end systolic volumes were calculated from three different paired echocardiographic projections: $(a)$ the two and four chamber views from the apical impulse window, $(b)$ the parasternal long axis view and the subxiphoid long axis view, and $(c)$ the four chamber view and short axis precordial views at mitral and papillary muscle level. Volumes were calculated in five different ways using three different algorithms (area length, Simpson's rule, the Parisi formula). The results were compared with data obtained from biplane angiograms using Graham's formula. The correlation varied with the algorithm used: the best results were obtained with the area length method using the parasternal long axis view and the sub-xiphoid view. The correlation was less accurate for the ejection fraction. The second best correlation was obtained with the area length method using the two and four chamber apical views; the other correlations were less satisfactory.

Thus these results show that left ventricular volumes can be accurately assessed by cross sectional echocardiography in children with tetralogy of Fallot and that the ejection fraction can be satisfactorily estimated. The results depend on careful gain setting and precise demonstration of the left ventricular endocardium, which is best seen in the sub-xiphoid and long axis views.

Determination of left ventricular volume and ejection fraction in children has relied mostly on left ventricular angiography which remains the gold standard. ${ }^{1-4}$ Real time echocardiography became available a few years ago for assessing cardiac malformations in adults $^{5-7}$ and in children, ${ }^{8-10}$ and more recently calculation of left ${ }^{11-13}$ and right ventricular volumes ${ }^{14} 15$ and ejection fraction became possible with this method. ${ }^{16-18}$ Accurate assessment of left ventricular volumes using cross sectional echocardiography in experimental animals ${ }^{19-22}$ and in adult patients with valvular or coronary artery disease has been reported. 122324 Some preliminary studies of children with various congenital heart defects have also been

Requests for reprints to Dr I Oberhänsli, Unité de Cardiologie Pediatrique, Hôpital Cantonal Universitaire, 30 Boulevard de la Cluse, 1205 Geneva, Switzerland.

Accepted for publication 20 March 1984 reported. ${ }^{13} 25$ Because these defects alter the position and loading condition of the left ventricle the ideal cross sections and algorithms to be used may vary from one type of heart disease to another. The cross sectional echocardiographic apical views have so far been found to be the best views for estimating left ventricular volumes and ejection fraction in children and adults. 121324 These views are, however, rather difficult to obtain in some cardiac malformations and in the very sick and anxious child. More recently, short axis views combined with a four chamber apical view were favoured for evaluating cardiac function. 171825

In this study we focused our attention on the left ventricle in patients with tetralogy of Fallot because left ventricular volume and function are of particular interest and importance in the postoperative outcome in these patients. ${ }^{326}$ Furthermore, we chose a group 
of patients that was homogeneous with regard to cardiac position in the chest and loading condition of the left ventricle.

\section{Patients and methods}

Twenty eight children ( 12 girls, 16 boys; age range 1 month to 14 years (mean age 6 years 11 months); mean weight $18.1 \mathrm{~kg}$, range $4.23-43.5 \mathrm{~kg}$ ) with tetralogy of Fallot who had undergone preoperative cardiac catheterisation with good left ventricular angiograms and good cross sectional echocardiograms were included in the comparative evaluation of left ventricular volumes and ejection fraction. One of these children also had significant mitral incompetence.

\section{ECHOCARDIOGRAPHY}

Real time echocardiography was performed 12 to 24 hours before angiography. A mechanical sector scanner (Advanced Technical Laboratories Mark 5) was used with either a $3 \mathrm{MHz}$ or $5 \mathrm{MHz}$ transducer. Apical long axis and parasternal long axis and short axis views and sub-xiphoid long and short axis views were recorded as previously described.68-1013 The patients were examined in the left lateral decubitus position for parasternal and apical views and in the supine position with bent knees for the sub-xiphoid views.

Images and calibrations were traced with the aid of a microprocessor controlled light pen system (Fig. 1) on a digitising table, the traced cavity being displayed directly on the video screen. This system was connected to a minicomputer (Cardio 80 system). End diastole was defined as the frame at which the reference electrocardiogram reached either the trough of the $Q$ wave or the upstroke of the $R$ wave when no $Q$ wave was present. End systole was defined as the frame at which the reference electrocardiogram reached the end of the $T$ wave or the smallest left

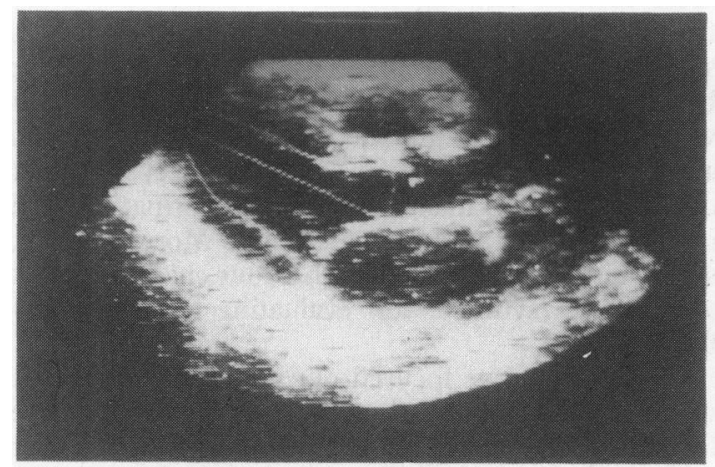

Fig. 1 Cross sectional echocardiogram with light pen tracing of the left ventricle in a long axis projection.

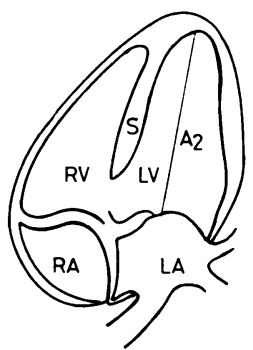

(a)

Four chamber view

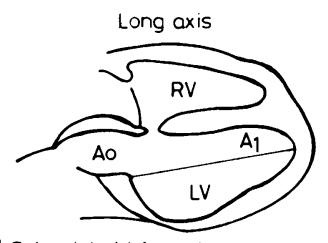

(b) Sub-xiphoid four chamber view

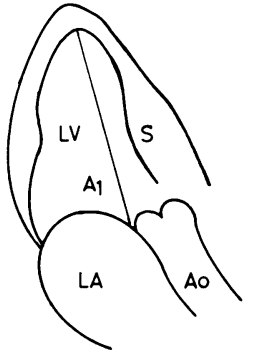

Two chamber view

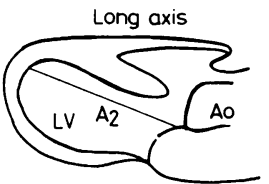

Parasternal view

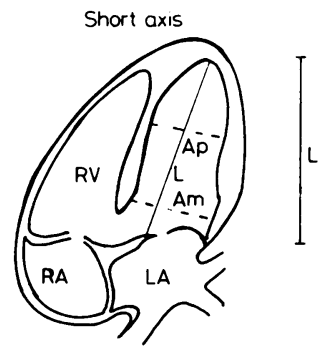

Apical 4 chamber view

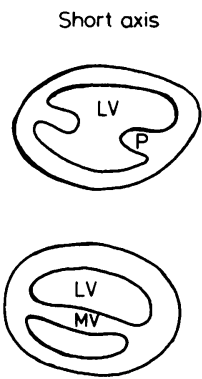

Parasternal view

Fig. 2 Diagram of the three different models used for volume calculations in five different algorithms: (a) apical four and two chamber views; (b) sub-xiphoid four chamber and parasternal long axis views-volumes in both models are calculated using the area length method: $V=\frac{8 A_{1} \cdot A_{2}}{3 \pi L}$

and Simpson's rule: $V=\frac{\pi}{4} \sum_{i=1}^{n}$ ai bi $\frac{L}{n}$;

(c) apical four chamber and parasternal short axis views. The , volume is calculated using the Parisi formula (modified Simpson's rule):

$$
V=(A m) \quad \frac{L}{3}+\frac{(A m+A p)}{2} \quad \frac{L}{3}+\frac{1}{3}(A p) \frac{L}{3} .
$$

$A_{1}, A_{2}$, planimetered areas: ai, bi, short axis diameters; $L$, length of common $L V$ axis; $V$, volume; $A m$, area at mitral valve level; $A p$, area at papillary muscular level; $R A$, right atrium; $R V$, right ventricle; $L A$, left atrium; $L V$, left ventricle; $S$, septum; $P$, papillary muscle; $M V$, mitral valve; Ao, aorta.

ventricular silhouette. The papillary muscles were excluded from the outline tracing in the short axis views only. 

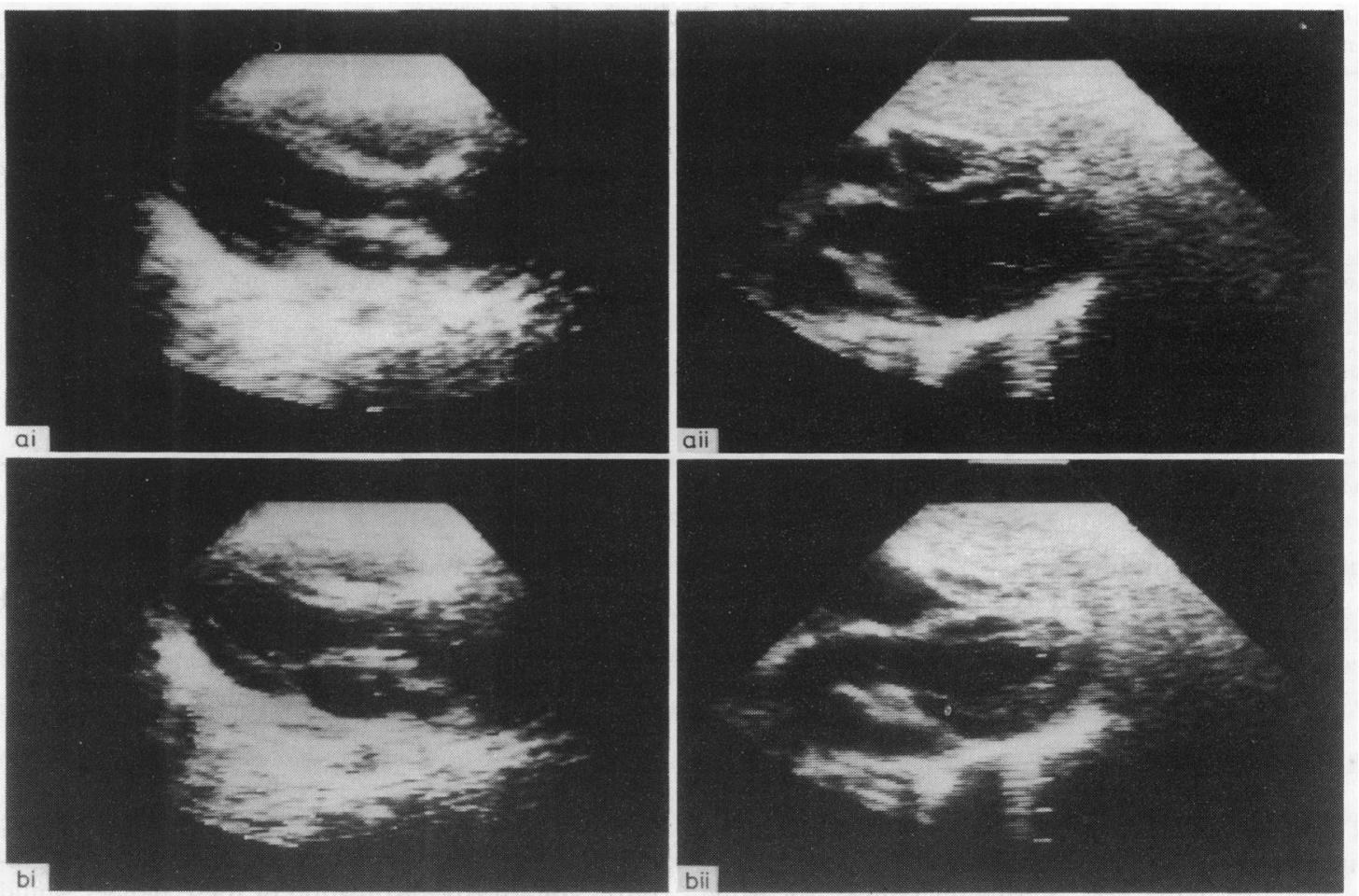

Fig. 3 Cross sectional echocardiographic orthogonal (a) end diastolic and (b) end systolic projections of the left ventricle obtained in the (i) parasternal long axis view and the (ii), sub-xiphoid long axis view.

\section{Volume calculations}

The Cardio 80 system allowed the analysis of the end systolic and end diastolic areas and calculated the corresponding volumes using five algorithms based on three geometric models (Fig. 2); one tracing could not be used for more than one algorithm. Thus for each new algorithm chosen the end diastolic and end systolic silhouettes had to be retraced. For each volume and ejection fraction of one particular algorithm two to five individual tracings were made and the corresponding calculations averaged.

Simpson's rule was applied to two paired sections of the diagram (Fig. 2a and b): the two and four chamber apical views and the sub-xiphoid and parasternal long axis views. Both are combinations of two perpendicular planes. This algorithm assumed the volume of the ventricle to be the sum of small cylinders and a truncated ellipse.

The biplane area length method was applied to the same sections as described under Simpson's rule. Fig. 3 shows the real time images using the sub-xiphoid and the parasternal long axis projections at end diastole and end systole.

A modified Simpson's rule (the Parisi formula) was used for the calculation of left ventricular volumes using the four chamber apical view and parasternal short axis views at mitral and papillary muscle level (Fig. 2c).

\section{CINEANGIOCARDIOGRAPHY}

During routine catheterisation under light sedation (pethidine, chlorpromazine, promethazine) left ventricular biplane cineangiocardiograms were obtained in the left and right oblique position at a $90^{\circ}$ angle at 50 or 75 frames/s. Special care was taken to avoid extrasystoles and to assure an adequate technical quality for calculating angiographic volumes. A sphere of $6 \mathrm{~cm}$ diameter was filmed at the position of the heart in both projections to correct for linear magnification. End diastolic and end systolic frames were used to calculate left ventricular end diastolic and end systolic volumes and the ejection fractions using the area length method ${ }^{27}$ with the modified regression equation of Graham et al. ${ }^{28}$

\section{STATISTICAL ANALYSIS}

Left ventricular end diastolic and end systolic volumes and the ejection fraction obtained from cross sectional echocardiograms with each algorithm were compared with biplane cineangiocardiographic vol- 
Table Correlation between angiographically and echocardiographically determined left ventricular volumes and ejection fraction using three geometric models and five different algorithms

\begin{tabular}{|c|c|c|c|c|c|c|c|c|c|c|c|c|}
\hline \multirow[t]{2}{*}{ Geometric model and algorithm } & \multirow[t]{2}{*}{$n$} & \multicolumn{4}{|c|}{ End diastolic volume } & \multicolumn{4}{|c|}{ End systolic volume } & \multicolumn{3}{|c|}{ Ejection fraction } \\
\hline & & $r$ & Slope & $\begin{array}{l}\text { Inter- } \\
\text { cept }\end{array}$ & $\begin{array}{l}S E E \\
(m l)\end{array}$ & $r$ & Slope & $\begin{array}{l}\text { Inter- } \\
\text { cept }\end{array}$ & $\begin{array}{l}S E E \\
(m l)\end{array}$ & $r$ & Slope & $\begin{array}{l}\text { Inter- } \\
\text { cept }\end{array}$ \\
\hline \multicolumn{13}{|l|}{$\begin{array}{l}\text { Two and four chamber apical } \\
\text { views }\end{array}$} \\
\hline $\begin{array}{l}\text { Area length method } \\
\text { Simpson's rule } \\
\text { Parasternal and sub-xiphoid } \\
\text { long axis view }\end{array}$ & $\begin{array}{l}22 \\
19\end{array}$ & $\begin{array}{l}0.87 \\
0.61\end{array}$ & $\begin{array}{l}0.81 \\
0.83\end{array}$ & $\begin{array}{l}13 \cdot 64 \\
16 \cdot 6\end{array}$ & $\begin{array}{l}14 \cdot 94 \\
18 \cdot 58\end{array}$ & $\begin{array}{l}0.93 \\
0.60\end{array}$ & $\begin{array}{l}0.92 \\
0.91\end{array}$ & $\begin{array}{l}3 \cdot 58 \\
5 \cdot 72\end{array}$ & $\begin{array}{r}7.89 \\
10.03\end{array}$ & $\begin{array}{l}0.72 \\
0.62\end{array}$ & $\begin{array}{l}0.82 \\
0.43\end{array}$ & $\begin{array}{r}7 \cdot 71 \\
32 \cdot 86\end{array}$ \\
\hline $\begin{array}{l}\text { Area length method } \\
\text { Simpson's rule } \\
\text { Four chamber view and } 2 \text { short } \\
\text { axis views }\end{array}$ & $\begin{array}{l}28 \\
25\end{array}$ & $\begin{array}{l}0.95 \\
0.87\end{array}$ & $\begin{array}{l}0.95 \\
0.91\end{array}$ & $\begin{array}{l}3 \cdot 32 \\
7 \cdot 72\end{array}$ & $\begin{array}{l}10.79 \\
12.64\end{array}$ & $\begin{array}{l}0.97 \\
0.87\end{array}$ & $\begin{array}{l}1.01 \\
1.01\end{array}$ & $\begin{array}{l}1.93 \\
3.50\end{array}$ & $\begin{array}{l}5 \cdot 37 \\
6 \cdot 17\end{array}$ & $\begin{array}{l}0.70 \\
0.55\end{array}$ & $\begin{array}{l}0.81 \\
0.51\end{array}$ & $\begin{array}{r}7 \cdot 13 \\
24 \cdot 52\end{array}$ \\
\hline Parisi formula & 25 & 0.68 & 0.74 & $31 \cdot 03$ & $24 \cdot 79$ & 0.84 & 0.85 & $13 \cdot 31$ & 10.92 & 0.64 & 0.71 & $11 \cdot 08$ \\
\hline
\end{tabular}

umes and ejection fractions.

Linear regression analysis was performed; standard errors of the estimate (SEE) and the correlation coefficients ( $r$ ) were calculated for the number of cases studied.

\section{Results}

The Table shows the correlation of volume determinations by cross sectional echocardiography and cineangiography. End diastolic volumes calculated from cineangiograms ranged from 28.7 to $175.7 \mathrm{ml}$, whereas systolic volumes ranged between 10.0 and $113.3 \mathrm{ml}$. Echocardiographically determined volumes varied with the algorithm used. The two geometric models using orthogonal views either from the apical window or the combined parasternal and sub-xiphoid long axis views provided good results using the area length method. The Simpson's rule algorithm was less satisfactory in this study. There were significant differences between volume calculations by the area length method and Simpson's rule (Table).

Fig. 4 shows the results for the two geometric models using the area length algorithm, cross sectional echocardiographic volumes and ejection fraction being plotted against angiographic values. Cross sectional echocardiography tends to underestimate slightly but significantly $(p<0.01)$ the cine angiographically determined values. The combined orthogonal cross sectional measurements in the subxiphoid and the parasternal long axis views (Fig. 4 $\mathrm{d}-\mathrm{f}$ ) in this study proved to be superior to those in the apical two and four chamber views (Fig. $4 \mathrm{a}-\mathrm{c}$ ) in determining volume and ejection fraction. The modified Simpson's rule (the Parisi formula) using the four chamber apical view and parasternal short axis views at the mitral and papillary muscle level showed a large scatter for all values (Table). In this projection the identification of the endocardial border is difficult and cannot always be obtained in children. Correlation between the values obtained by cross section-l echocardiography and cineangiography are show 1 the Table and Fig. 4 for end diastolic and end syst volumes as well as ejection fractions.

\section{Discussion}

Until now the determination of left ventricular volumes and ejection fraction has relied on cineangiography. Non-invasive estimation of these indices would be useful so that repeated measurements could be taken without catheterisation. Many attempts have been made to determine the accuracy of the echocardiography in assessing ventricular function, first by $M$ mode ${ }^{2-31}$ and more recently by cross sectional sector scanning. ${ }^{19-22}$ These reports have shown satisfactory correlation between the cross sectional echocardiographic assessment of left ventricular volumes and function indices and angiocardiographically calculated values. ${ }^{11} 12^{16^{-18}}$ Most of the studies were carried out either in animals ${ }^{19-22}$ or in adults with coronary and valvular heart disease. 17233233 Only very few studies deal with children with a variety of congenital cardiac malformations. 131425

Various mathematical formulas for the calculation of volume from cross sectional echocardiograms have been used and compared with angiographically obtained values. 1920 Whatever the formula used, considerable variations have been noted between results of these two methods. 121833 The causes of the variability found in several recent studies have been more extensively investigated by some researchers. ${ }^{32} 3435$ The factors found to influence the accuracy of measurements include technical characteristics of a machine and the scan head, problems with axial, lateral, and cross plane resolution, tissue interactions, limited sampling rate, gain setting, insufficient dynamic range of available display devices, and 

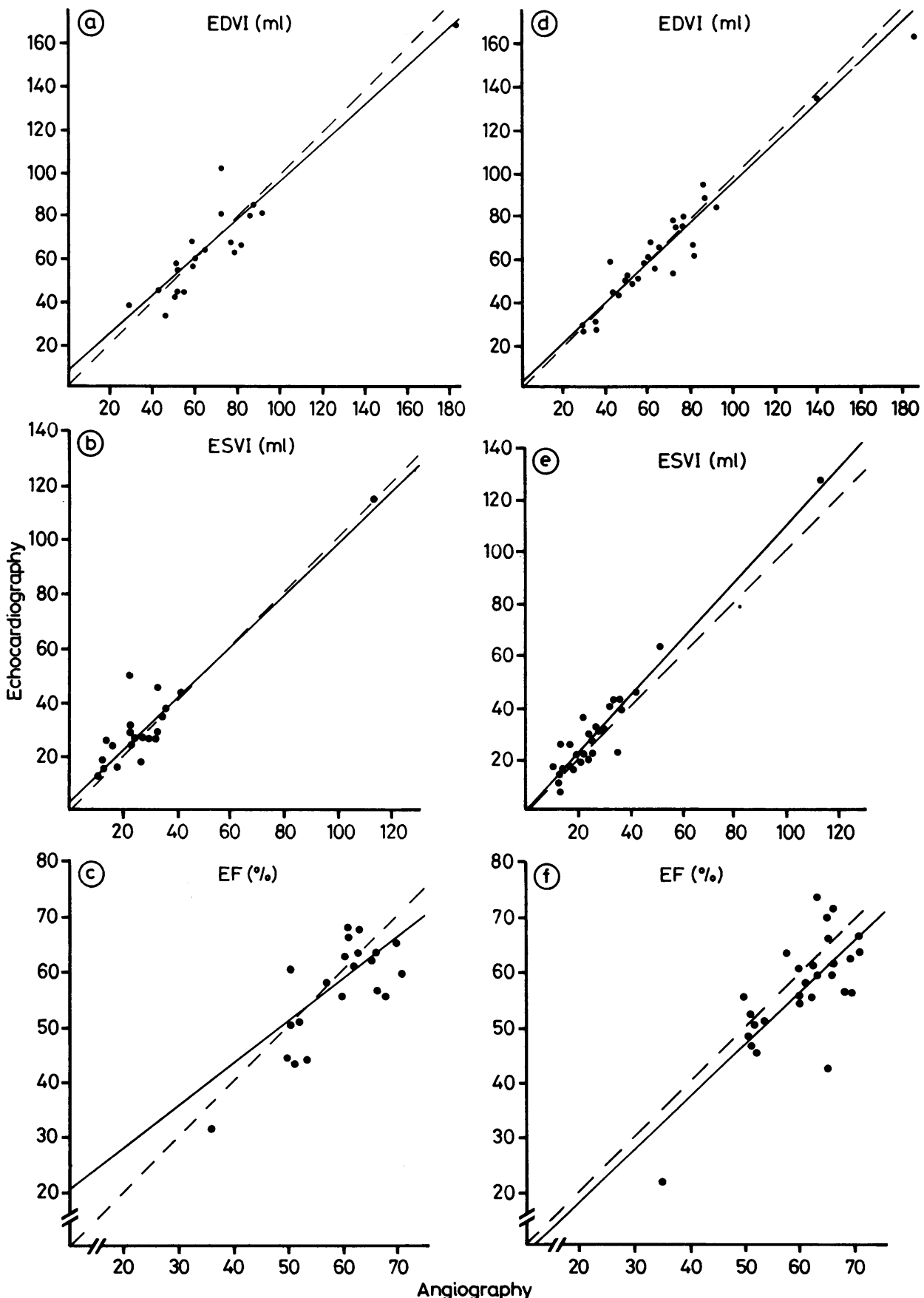

Fig. 4 Indexed biplane angiographic end diastolic (EDVI) and end systolic (ESVI) volumes and ejection fraction plotted against indexed volumes and ejection fractions calculated with the area length method from cross sectional echocardiograms in $(a-c)$ the two and four chamber apical views and $(d-f)$ the parastermal and orthogonal sub-xiphoid long axis views of the left ventricle. 
artefacts related to the video recording system. In addition, factors relating to the patient himself-that is, the size of the echo window, changes in cardiac geometry, the patient's cooperation, and uncertainty of spatial orientation in three dimensions-contribute greatly to differences in quantitative evaluations. ${ }^{33-35}$ Such considerations are especially important in children. Changes in cardiac geometry are pronounced in patients with different cardiac malformations and abnormal loading conditions, ${ }^{36}$ and this is an important consideration in patients with tetralogy of Fallot. In this malformation the hypertrophied and dilated right ventricle lies more anteriorly and pushes the left ventricle upwards and backwards, thus changing the intrathoracic and intracardiac geometry. The aorta is displaced anteriorly and overrides the ventricular septal defect and the septum.

Standard cross sectional echocardiographic projections of these hearts are more difficult to obtain; some may be impossible, the echo window frequently being small in these children. The apical window is displaced; thus the two and four chamber views are less reproducible and sometimes distorted. The identification of the endocardium can become extremely difficult and needs continuous gain setting. Short axis views of the left ventricle are also displaced, distorted, and more difficult to define. Volume calculations of one or other projection can therefore become difficult, uncertain, less reproducible, or even unrealistic.

We tried to find the most simple and reliable projection of the left ventricle in two orthogonal cross sections for volume calculations in patients with tetralogy of Fallot. The sub-xiphoid long axis view and a low parasternal long axis view appear to be easily reproducible perpendicular planes in these patients, and the endocardium is well outlined. These two planes appear, therefore, to be the best cross sections for volume calculation.

Correlation coefficients varied with the algorithm and the geometric model used (Table). Compared with published data, the correlations were generally comparable but weaker (Fig. 4). Echocardiographic volume calculations underestimated angiographic volumes only slightly but less than in other reports. 121325 Being aware of the technical difficulties in defining the left ventricular endocardium, we used a rather low gain setting for the cross sectional echocardiogram, and also repeatedly changed the light setting at the video screen before each tracing. Thus the left ventricular area probably became larger than in previous studies. Nevertheless, there was quite a wide variability between individual calculations. The correlations between echocardiographic and angiographic data improved when several individual volume calculations for different cardiac cycles were averaged. For the area length method, in general, a mean of five measurements was used, whereas for the Simpson's rule only two, sometimes three, cardiac cycles could be averaged. This might have contributed to the fact that Simpson's rule correlated less well in the present study. Also, the fact that the area length method was used for calculating angiographic volumes ${ }^{31} 32$ may contribute to a better correlation with real time echocardiography when the same algorithm is used.

The rather wide scatter of individual measurements, however, stresses the fact that imaging of the left ventricle is significantly more difficult in patients with tetralogy of Fallot than in children with cardiac malformations with left ventricular volume overload. In different cardiac malformations the intrathoracic position and the shape of the ventricles vary as well as the loading conditions; it therefore becomes necessary to find a simple method of easily assessing the left ventricle in two orthogonal planes. An "ideal" orthogonal plane might not always prove to be the same projection in various cardiac lesions. In right ventricular pressure and volume overload combined sub-xiphoid and parasternal long axis views proved to be the most useful approach considering the results of this study. These two projections can be obtained easily and repeatedly with good reproducibility. Whether these projections can, however, also be used for other congenital and acquired malformations needs further investigation and careful assessment.

This study was supported by the Swiss National Science Foundation.

\section{References}

1 Kaye HH, Tynan M, Hunter S. Validity of echocardiographic estimates of left ventricular size and performance in infants and children. $\mathrm{Br}$ Heart $\mathcal{F}$ 1975; 37: 371-5.

2 Meyer RA, Stockert J, Kaplan S. Echographic determination of left ventricular volumes in pediatric patients. Circulation 1975; 51: 297-303.

3 Oberhänsli I, Friedli B. Echocardiographic study of right and left ventricular dimension and left ventricular function in patients with tetralogy of Fallot, before and after surgery. Br Heart $\mathcal{J}$ 1979; 41: 40-53.

4 Bhatt DR, Isabel-Jones JB, Villoria GJ, et al. Accuracy of echocardiography in assessing left ventricular dimensions and volume. Circulation 1978; 57: 699-707.

5 King DL, Jaffee CC, Schmidt DH, Ellis K. Left ventricular volume determination by cross-sectional cardiac ultrasonography. Radiology 1972; 104: 201-2.

6 Feigenbaum HL. Echocardiography. 3rd ed. Philadelphia: Lea and Febiger, 1981.

7 Henry WL, Maron BJ, Griffith JM. Cross-sectional echocardiography in the diagnosis of congenital heart disease. Circulation 1977; 56: 267-73.

8 Silverman NH, Schiller NB. Apex echocardiography: a 
two-dimensional technique for evaluating congenital heart disease. Circulation 1978; 57: 503-11.

9 Tajik AJ, Seward JB, Hagler DJ, Mair DD, Lie JT. Two-dimensional real-time ultrasonic imaging of the heart and great vessels. Technique, image orientation, structure identification and validation. Mayo Clin Proc 1978; 53: 271-308.

10 Bierman FZ, Williams RG. Subxiphoid two-dimensional imaging of the interatrial septum in infants and neonates with congenital heart disease. Circulation 1979; 60: 8091.

11 Gehrke J, Leeman S, Raphael M, Pridie RB. Noninvasive left ventricular volume determination by twodimensional echocardiography. Br Heart $\mathcal{F}$ 1975; 37: 911-6.

12 Schiller NB, Acquatella H, Ports A, et al. Left ventricular volume from paired biplane two-dimensional echocardiography. Circulation 1979; 60: 547-55.

13 Siverman NH, Ports TA, Snider AR, Schiller NB, Carlsson E, Heilbron DC. Determination of left ventricular volume in children: echocardiographic and angiographic comparisons. Circulation 1980; 62: 548-57.

14 Hiraishi S, DiSessa TG, Jarmakani JM, Nakanishi T, Isabel-Jones JB, Friedman WF. Two-dimensional echocardiographic assessment of right ventricular volume in children with congenital heart disease. Am $\mathcal{F}$ Cardiol 1982; 50: 1368-75.

15 Krebs W, Erbel R, Schweizer P, et al. Volumenbestimmung des rechten Ventrikels mit Hilfe der Subtraktionsmethode-Eine vergleichende zweidimensionale echokardiographische und röntgenologische Studie an Herzmodellen. Zeitschrift für Kardiologie 1982; 71: 413-20.

16 Carr KW, Engler RL, Forsythe JR, Johnson AD, Gosink B. Measurement of left ventricular ejection fraction by mechanical cross-sectional echocardiography. Circulation 1979; 59: 1196-206.

17 Folland ED, Parisi AF, Moynihan PF, Jones DR, Feldman CL, Tow DE. Assessment of left ventricular ejection fraction and volumes by real time, two-dimensional echocardiography. A comparison of cineangiographic and radionuclide techniques. Circulation 1979; 60: 7606.

18 Parisi AF, Moynihan PF, Feldman CL, Folland ED. Approaches to determination of left ventricular volume and ejection fraction by real time two-dimensional echocardiography. Clin Cardiol 1979; 2: 257-63.

19 Wyatt HL, Heng MK, Meerbaum S, et al. Crosssectional echocardiography I. Analysis of mathematic models for quantifying mass of the left ventricle in dogs. Circulation 1979; 60: 1104-13.

20 Wyatt HL, Heng MK, Meerbaum S, et al. Crosssectional echocardiography II. Analysis of mathematic models for quantifying volume of the formalin-fixed left ventricle. Circulation 1980; 61: 1119-25.

21 Eaton LW, Maughan WL, Shoukas AA, Weiss JL. Accurate volume determination in the isolated ejecting canine left ventricle by two-dimensional echocardiography. Circulation 1979; 60: 320-6.

22 Sold G, Zwehl W, Vogt A, Kamp M, Neuhaus KL, Kreuzer H. Bestimmung linksventrikulärer Volumina mittels zweidimensionaler Echokardiographie beim
Hund: Korrelation zur biplanen Angiokardiographie. $Z$ Kardiol 1981; 70: 357-63.

23 Erbel R, Schweizer P, Meyer J, Grenner H, Krebs W, Effert S. Left ventricular volume and ejection fraction determination by cross-sectional echocardiography in patients with coronary artery disease: a prospective study. Clin Cardiol 1980; 3: 377-83.

24 Jenni R, Vieli A, Turina J, Anliker M, Krayenbuehl HP. Determination of left ventricular volume from apical orthogonal two-dimensional echocardiograms. In: Rijsterborgh H, ed. Echocardiology. The Hague, Boston, London: Martinus Nijhoff, 1980:163-6.

25 Mercier JC, DiSessa TG, Jarmakani JM, et al. Twodimensional echocardiographic assessment of left ventricular volumes and ejection fraction in children. Circulation 1982; 65: 962-9.

26 Jarmakani JMM, Graham TP Jr, Canent RV Jr, Jewett $\mathrm{PH}$. Left heart function in children with tetralogy of Fallot before and after palliative or corrective surgery. Circulation 1972; 46: 478-90.

27 Dodge HT, Sandler H, Ballew DW, Lord JD Jr. The use of biplane angiocardiography for the measurement of left ventricular volume in man. Am Heart f 1960; 60: 762-76.

28 Graham TP Jr, Jarmakani JM, Canent RV Jr, Morrow $M N$. Left heart volume estimation in infancy and childhood. Reevaluation of methodology and normal values. Circulation 1971; 43: 895-904.

29 Feigenbaum H, Popp RL, Wolfe SB, et al. Ultrasound measurements of the left ventricle. A correlative study with angiocardiography. Arch Intern Med 1972; 129: 461-7.

30 Gibson DG. Estimation of left ventricular size by echocardiography. Br Heart $\mathcal{F}$ 1973; 35: 128-34.

31 Teichholz LE, Kreulen T, Herman MV, Gorlin R. Problems in echocardiographic volume determinations: echocardiographic-angiographic correlations in the presence or absence of asynergy. Am $\mathcal{F}$ Cardiol 1976; 37: 7-11.

32 Gueret P, Meerbaum S, Wyatt HL, Uchiyama T, Lang TW, Corday E. Two-dimensional echocardiographic quantitation of left ventricular volumes and ejection fraction. Importance of accounting for dysynergy in short axis reconstruction models. Circulation 1980; 62: 130819.

33 Erbel R, Krebs W, Henn G, et al. Comparison of single-plane and biplane volume determination by twodimensional echocardiography: asymmetric model hearts. Eur Heart f 1982; 3: 469-80.

34 Geiser EA, Skorton DJ, Conetta DA. Quantification of left ventricular function by two-dimensional echocardiography: consideration of factors restricting image quality. Am Heart f 1982; 103: 905-10.

35 Stamm RB, Carabello BA, Mayers DL, Martin RP. Two-dimensional echocardiographic measurement of left ventricular ejection fraction: prospective analysis of what constitutes an adequate determination. Am Heart $\mathcal{F}$ 1982; 104: 136-44.

36 Lange PE, Onnasch DGW, Schaupp GH, Zill C, Heintzen PH. Size and function of the human left and right ventricles during growth. Normative angiographic data. Pediatr Cardiol 1982; 3: 205-11. 